\title{
Indinavir-Associated Toxicity Mimicking Urinary Tuberculosis in a Patient with AIDS
}

\author{
Vinicius Daher Alvares Delfino ${ }^{1}$, Natally Marques Santiago ${ }^{1}$, Altair Jacob Mocelin ${ }^{1}$, Luiz Fernando Kunii ${ }^{1}$ and André Luiz Bortoliero ${ }^{2}$ \\ ${ }^{I}$ Nephrology Department; ${ }^{2}$ Infectious Disease Department, State University of Londrina; Londrina, PR, Brazil
}

\begin{abstract}
This case reported to a patient with AIDS who presented persistent sterile leukocyturia and hematuria, lower back pain, bladder suffering symptoms, and renal papillary necrosis which were thought to be secondary to urinary tuberculosis but were demonstrated to be indinavir-associated side effects. The intention of this report is to remind medical professionals involved in the care of HIV+ patients of this possible association in order to avoid unnecessary investigation and to stress the need of careful periodical assessment of renal function and urinalysis in patients treated with indinavir.
\end{abstract}

Key-Words: Hematuria, indinavir, kidney papillary necrosis, tuberculosis.

As nowadays sustained viral suppression can be obtained through chronic highly active antiretroviral treatment to patients with HIV infection, long-term drug side effects should be feared. Indinavir (IDV) is one of the most widely used protease inhibitor. Reported side effects include lipodystrophy, hyperbilirrubinemia, gastrointestinal malaise, diarrhea and headache. Nephrolithiasis is the most common renal side effect, being reported in 4-9\% of individuals [1], but the spectrum of renal and urinary adverse effects of IDV is much larger, as it can be appreciated in the case here presented.

\section{Case Report}

A 47 year-old asian-descendant man was diagnosed as having AIDS in October 1996 and started on a fixed combination of zidovudine $300 \mathrm{mg}$ and lamivudine $150 \mathrm{mg}$, twice daily, plus indinavir (IDV), $800 \mathrm{mg}$ thrice daily. This therapeutic regimen led to gradual normalization of $\mathrm{CD}_{4}+$ cells and, from September 1998 onwards, to undetectable RNA virus levels on the blood. The patient's clinical course went uneventful until May 2001 when sterile leukocyturia and hematuria were found on routine urinalysis. The sterile leukocyturia and hematuria were persistent and raised the suspicious of urinary tuberculosis. The urinary tract was shown to have normal ultrasonographic appearance and a cystoscopy was performed but was unrevealing; multiple urinary cultures for Mycobacterium were ordered but were negative. From August 2002 on he started presenting repeated episodes of bilateral lower back pain. An intravenous pyelography was ordered but did not reveal stones or any other abnormality. On February 2003 his serum creatinine increased from $1.16 \mathrm{mg} / \mathrm{dL}$ (June 1997; estimated glomerular filtration rate, MDRD simplified formula, eGFR, $72 \mathrm{~mL} / \mathrm{min} /$ $1.73 \mathrm{~m}^{2}$ ) to $1.57 \mathrm{mg} / \mathrm{dL}$ (eGFR $49 \mathrm{~mL} / \mathrm{min} / 1.73 \mathrm{~m}^{2}$ ) and he complained of dysuria, polyuria and urgency. Urinary tuberculosis was again searched, but results of urinary Received on 11 November 2007; revised 28 January 2008.

Address for correspondence: Dr. Vinicius Daher Alvares Delfino. Instituto do Rim de Londrina. Avenida Bandeirantes, 804. Zip code: 86.010010, Londrina, PR, Brazil. E-mail: vddelfino@ sercomtel.com.br. Telephone/facsimile: 5543 33239191. Cell phone: 554399918416 Publishing. All rights reserved. cultures for ordinary urinary pathogens, Mycobacterium, and fungi were negative, despite the findings of 721,000 leukocytes and 560,000 red blood cells per $\mathrm{mL}$ of his urine. By the end of 2003 he had accentuation of his urinary symptoms. Cystoscopy was repeated: normal; an intravenous pyelography showed spots of bilateral papillary necrosis. At the beginning of 2005, he was sent to seek nephrology consultation. At that occasion his serum creatinine was 1.71 $\mathrm{mg} / \mathrm{dL}$ (eGFR, $44 \mathrm{~mL} / \mathrm{min} / 1.73 \mathrm{~m}^{2}$ ). It was suspected that the renal and urologic patient's abnormalities might be due to indinavir-associated toxicity. After discussion of the case with the infectologist in charge for the case it was agreed to change from indinavir to atazanavir (400 mg/day). With the change, he had progressive normalization of his urinary sediment and disappearance of urinary symptoms, while keeping undetectable serum HIV-RNA blood levels. The course of leukocyturia and eGFR after medication change are depicted on Figure 1. It should be said, however, that even after more then 20 months of indinavir withdrawal his serum creatinine persisted elevated $\left(1.5 \mathrm{mg} / \mathrm{dL}\right.$; eGFR $\left.51 \mathrm{~mL} / \mathrm{min} / 1.73 \mathrm{~m}^{2}\right)$ and there was abnormal renal corticomedullar differentiation at the ultrasound.

\section{Discussion}

In this AIDS patient, the sterile leukocyturia/hematuria accompanied by bladder suffering symptoms, and recurrent lower back pain were suggestive for urinary tuberculosis, which may also cause renal papillary necrosis. However, the complete disappearance of the urinary symptoms and the normalization of the patient's urinalysis (which were long time persistent) with the stop of IDV strongly point out for a causal relationship between IDV use and patient's renal/urologic nephrotoxicity. Indeed, all patient's findings, including renal papillary necrosis, have been reported as associated with indinavir use $[2,3]$. The fact that there was only a slight improvement in patient's renal function even many months after the discontinuation of IDV, in conjunction with ultrasound findings of abnormal renal corticomedullar differentiation may suggest that chronic renal parenchymal damage related to the drug use may have occurred [4]. Indinavir is metabolized primarily in the liver, but renal excretion of parent drug accounts for approximately $10 \%$ of a dose. In order to avoid renal and urological side-effects of the drug, it is 
Figure 1. Course of patient's leukocyturia and estimated glomerular filtration rate (eGFR) after removal of indinavir (large arrow) from therapeutic schedule

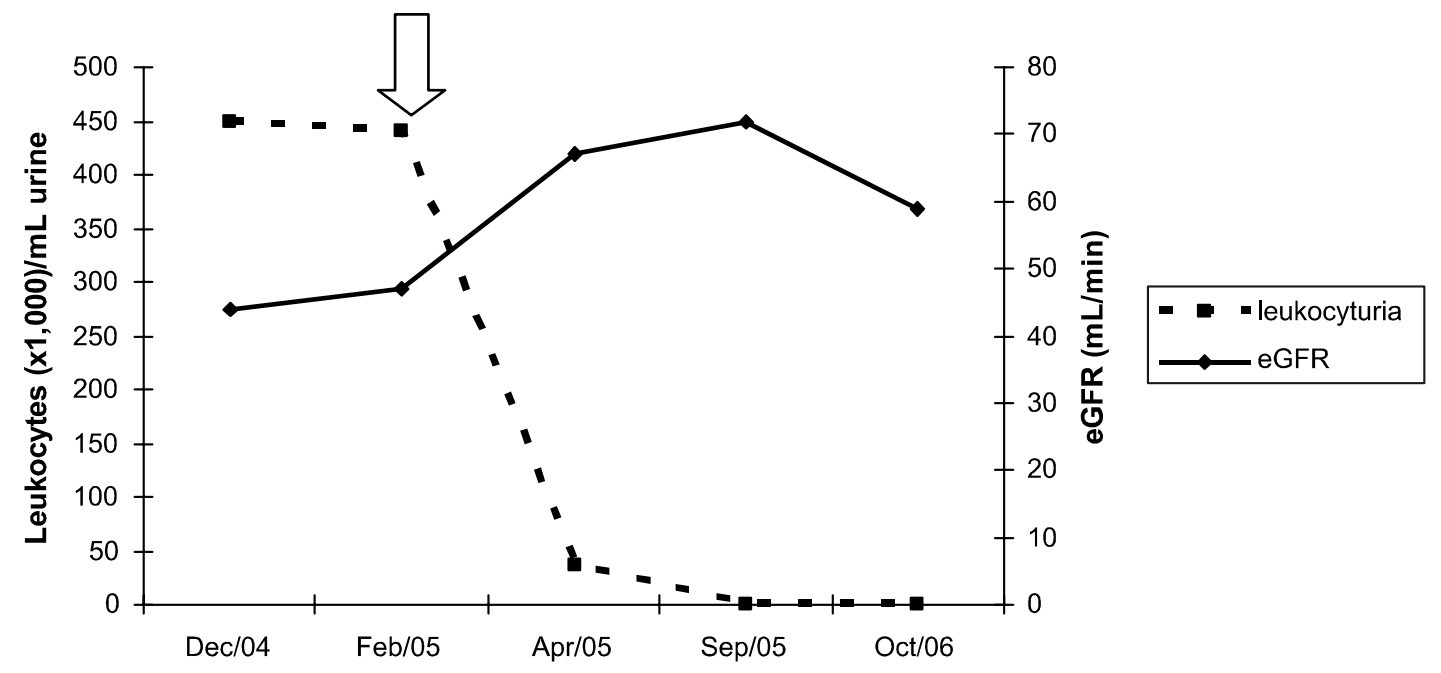

recommended for patients who start on indinavir a periodically monitoring during the first six months of therapy, then biannualy thereafter for changes in renal function and pyuria. Prevention of indinavir crystalluria and nephrolithiasis depends on maintenance of a daily fluid intake of at least 1.5 to $2 \mathrm{~L}$ [3].

\section{References}

1. Boubaker K., Sudre P., Bally F., et al. Changes in renal function associated with indinavir. AIDS 1998;12:249-50.
2. Dieleman J.P., van der Feltz M., Bangma B.H.C., van der Ende M.E. Papillary necrosis associated with the HIV protease inhibitor Indinavir. Infection 2001;4:232-3.

3. Berns J.S., Kasbekar N. Highly active antiretroviral therapy and the kidney: an update on antiretroviral medications for nephrologists. Clin J Am Soc Nephrol 2006; $1: 117-29$.

4. Reilly R.F., Tray K., Perazella M.A. Indinavir nephropathy revisited: a pattern of insidiuous renal failure with identifiable risk factors. Am J Kidney Dis $2001 ; 38: 1-6$. 